\title{
Effects of environmental conditions on inducing charge structures of thunderstorms over Eastern India
}

\author{
Sunil Dnyandeo Pawar', Venkatachalam Gopalakrishnan ${ }^{1 *}$, Palani Murugavel ${ }^{1}$, Andrei Sinkevich ${ }^{2}$ and Deen Mani Lal ${ }^{1}$
}

\begin{abstract}
It is well known that environmental conditions like convective instability, aerosol loading, and availability of moisture content affect the polarity of charge structures of thunderstorms. The electrical characteristics of thunderstorms observed during the pre-monsoon season of year 2009, over Eastern India were studied to identify the effects of different environmental conditions on charge structures of thunderstorms occurring over this region. Electric field and Maxwell current data suggest that at least one of these thunderstorms had an inverted charge structure. Doppler RADAR, radiosonde, and Moderate Resolution Imaging Spectroradiometer (MODIS) Aerosol Optical Depth (AOD) data have been used to compare the microphysical and dynamical characteristics of these thunderstorms. The thermo dynamical structure observed by radiosonde during the day on which an inverted polarity thunderstorm was observed showed very high CAPE in the mixed-phase region compared to other thunderstorm days. Furthermore, the AOD peaked 1 day before this thunderstorm. The back trajectories of winds also suggest that the aerosols might have been transported from a desert region on that day. It has been proposed that the large ice nuclei concentration can produce dominant positive charge in the lower portion of the mixed-phase region by maintaining ice saturation.
\end{abstract}

\section{Background}

It has long since been known that some of the more severe thunderstorms can have different charge structures than generally observed in ordinary thunderstorms. From the observations of electric field changes produced by lightning during a severe thunderstorm, Vonnegut and Moore (1958) suggested that severe thunderstorms could have an inverted charge structure. In three storms that occurred during the Severe Thunderstorm Electrification and Precipitation Study (STEPS), Rust et al. (2005) have observed the positive and negative charge regions at altitudes where negative and positive charge would normally be found in ordinary thunderstorms. Lang et al. (2004) and Wiens et al. (2005) reported storms with consistent dominant upper level inverted dipole charge structure near the updraft (i.e., the upper negative charge region and the main positive charge region below it). There are many other reports of inverted polarity charge structure in severe thunderstorms which

\footnotetext{
* Correspondence: gopal@tropmet.res.in

${ }^{1}$ Indian Institute of Tropical Meteorology, Pune, India

Full list of author information is available at the end of the article
}

produce positive Cloud-to-Ground (CG) flashes comparable to negative CG flashes (e.g., MacGorman and Burgess 1994; Stolzenburg 1994; Carey and Rutledge 1998; Lang and Rutledge 2002; Carey et al. 2003). Over a region from the Kansas/Colorado border to Minnesota, Carey and Rutledge (2003) found that the properties of CG lightning flashes produced from severe storms during warm seasons (i.e., large hail or tornado producing) were different from those produced by non-severe storms. They found that the percentage of CG lightning flashes lowering positive charge to ground was up to three times higher in severe storms. The median positive peak current in severe storms was larger by about $25 \%$. Furthermore, the median negative peak current in severe storms was very low (i.e., as low as 12 to $16 \mathrm{kA}$ ) and was noticeably less than in nonsevere storms (i.e., by at least $10 \%$ ).

Although earlier reports suggest most thunderstorms with inverted polarity charge structures were characterized by a high degree of severity, Qie et al. (2005) and Pawar and Kamra (2004 and 2009) have also reported some non-severe thunderstorms over the Tibetan Plateau and India, with a wide spread and strong positive charge 
in the lower portion of cloud. Majority of lightning activity arises from lower negative dipole of these thunderclouds. These thunderstorms can also be termed inverted polarity thunderstorms because for most of their lifetimes, lower negative dipole dominated the lightning activity of these storms.

Williams et al. (2005) hypothesized that the inverted polarity charge structure in thunderstorms is the result of superlative liquid water content in the mixed-phase region. Many observational studies support this idea (Krehbiel et al. 2000; Rust and MacGorman 2002; Lang et al. 2004). However, as emphasized by Williams et al. (2005), a strong updraft, an extraordinarily dry environment, or a high concentration of aerosols are necessary but not sufficient conditions for formation of inverted polarity thunderstorms. Many observations clearly show that thunderstorms fulfilling all the conditions above do not always form inverted polarity thunderstorms (MacGorman and Burgess 1994). Furthermore, the observations by Pawar and Kamra $(2004,2009)$ and Qie et al. (2005) show that some ordinary thunderstorms without strong updrafts can also have inverted polarity charge structures. All these observations clearly suggest that formation of inverted polarity is not fully understood.

In this paper, we report our observations of surface electric field and Maxwell current density made at Kharagpur $\left(22.31^{\circ} \mathrm{N}, 87.31^{\circ} \mathrm{E}\right)$ in Eastern India, beneath three thunderstorms that occurred during the premonsoon season of 2009. Electric field and Maxwell current data suggest that at least one of these thunderstorms had an inverted polarity charge structure. Doppler RADAR, radiosonde, and Moderate Resolution Imaging Spectroradiometer (MODIS) Aerosol Optical Depth (AOD) data have been used to compare the microphysical and dynamical characteristics of these three thunderstorms. Possible causes that may be responsible for formation of an inverted dipole charge structure in one of these thunderstorms are also discussed.

\section{Methods}

As described in detail by Pawar and Kamra (2007), an electric field mill flushed with the ground level and a plate antenna are used for electric field and Maxwell current measurements, respectively. Measurements of both these parameters are made throughout the day at a sampling rate of $10 \mathrm{~Hz}$. In our measurements, we consider the fair-weather electric field and the associated conduction current that brings positive charge to the ground, as negative polarity. In addition, we take the positive displacement current to be affected by a positive field change, lowering positive charge to the ground and vice-versa. For our analysis, AOD data is taken from MODIS, which acquires data in 36 high- resolution spectral bands between 0.415 and $14.235 \mu \mathrm{m}$. These data are obtained from a level-3 MODIS gridded atmosphere daily global joint product (MOD08_D3). We took the daily averaged AOD at $550 \mathrm{~nm}$ from MODISTerra Version 5. Those data for which cloud cover was greater than $20 \%$ were excluded from analysis while averaging.

\section{Results}

Observations of surface electric field and Maxwell current were made at Kharagpur, India, during the premonsoon season of 2009. This region is known for the occurrence of severe thunderstorms during April to May, known as Nor'westers. Figure 1 shows the location of observation and climatological surface winds during the observational period. As shown in Figure 1, surface winds are predominantly southeasterly, which bring moisture from the Bay of Bengal to this region. High moisture content of the surface layer and high temperatures during the pre-monsoon months make conditions favorable for the formation of severe thunderstorms. The large-scale flows and synoptic systems also play important roles in the frequency and intensity of these severe thunderstorms. Nor'westersis commonly associated with troughs and wind convergence lines in the lower troposphere, occurring together with a westerly trough and jet stream in the upper troposphere. Superposition of favorable upper and lower tropospheric conditions generally results in widespread outbreaks of Nor'westers. Figure 2 shows the vertical profiles of air and dew point temperatures obtained from upper air radiosonde measurements made over Kolkata at 0530 hours Indian Standard Time (IST) on 11 May 2009 and 6 May 2009, about $100 \mathrm{~km}$ from the study site. As shown in Figure 2, CAPE values were conducive to the formation of thunderstorms on 11 May 2009 and 6 May 2009, i.e., 3,124 J/ $\mathrm{Kg}$ and $3299 \mathrm{~J} / \mathrm{Kg}$, respectively. All times of observation in this study are reported in IST (UTC + 05:30).

\section{Electric field changes induced by lightning discharges}

Vonnegut and Moore (1958) proposed inverted charge structure from electric field measurements made about $90 \mathrm{~km}$ away from a severe thunderstorm, i.e., a charge structure with negative charge in the upper part of a thunderstorm rather than the normally observed positive charge in the upper part of a thunderstorm. Subsequent observations by Rust et al. (1981) and MacGorman and Burgess (1994), showing all or most of the CG lightning flashes during extensive periods of some storms, lowering positive charge to ground, instead of the usual negative charge, supported the idea that some thunderclouds can have inverted polarity charge structures. In recent years, observations made by the lightning mapping array of the New Mexico Institute of Mining and Technology 


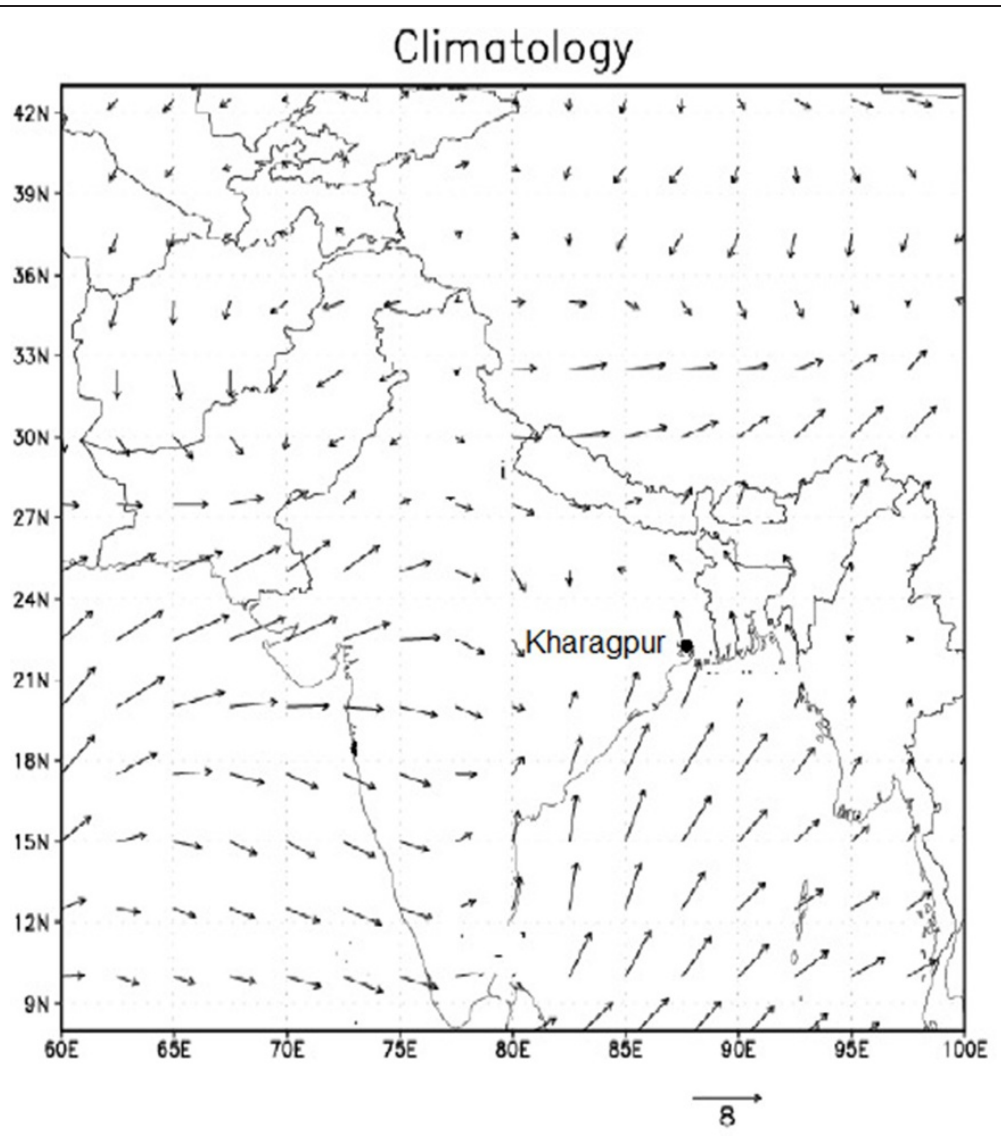

Figure 1 Map of India showing position of study site and NCEP reanalysis of climatological winds. At atmospheric pressure of 1,000 mb.

(NMT) have confirmed that some severe thunderstorms can have inverted dipole charge structures. Figure 3 shows the electric field measured at the surface during three thunderstorms which occurred on 11 May 2009, 6 May 2009, and 12 May 2009, respectively. Due to heavy rainfall, the field mill stopped working for some time for all 3 days. On May 11, the electric field started to build up from about 1530 hours and at about 1545 hours, the first electric field change induced by lightning was observed. As shown in Figure 3, this thunderstorm lasted for more than $4 \mathrm{~h}$. The maximum of lightning frequency occurred at about 1650 hours, when the thunderstorm was fully developed and closer to the study site. On May 6, a thunderstorm formed at about 1430 hours and lasted about $2 \mathrm{~h}$. Similarly, on May 12, a thunderstorm formed at about 1200 hours and lasted about $2.5 \mathrm{~h}$. It has also been observed that on May 11, most of the electric field changes induced by lightning were positive, suggesting removal of positive charge from overhead. Whereas most of the electric field changes induced by lightning were negative on May 6 and May 12, indicating removal of negative charge from overhead. It should be noted here that all three thunderstorms remained above the observatory during their most active period. Therefore, the sign of electric field changes induced by lightning clearly suggest that the dominating lowermost charge region was positive for the thunderstorm on May 11 and negative for the thunderstorms on May 6 and May 12.

In Figure 4, the electric field is plotted on an extended time scale during the active stages of these three thunderstorms. As shown in Figure 4, on 11 May 2009, electric field changes induced by lightning clearly show removal of positive charge from overhead, and recovery curves of the electric field show a buildup of positive charge. The two lightning discharges shown in Figure 4 were visually observed as CG discharges on May 11. As shown in Figure 4, these discharges transferred positive charge to the ground. Even though this region does not have a lightning detection network, we visually observed and noted whether lightning was CG or Intra Cloud (IC). Although most electric field and Maxwell current records suggest lowering of positive charge to the ground after the CG discharges on May 11, it is lowering negative charge from overhead, while building up negative charge overhead on 6 May 2009 and 12 May 2009. 
(a)
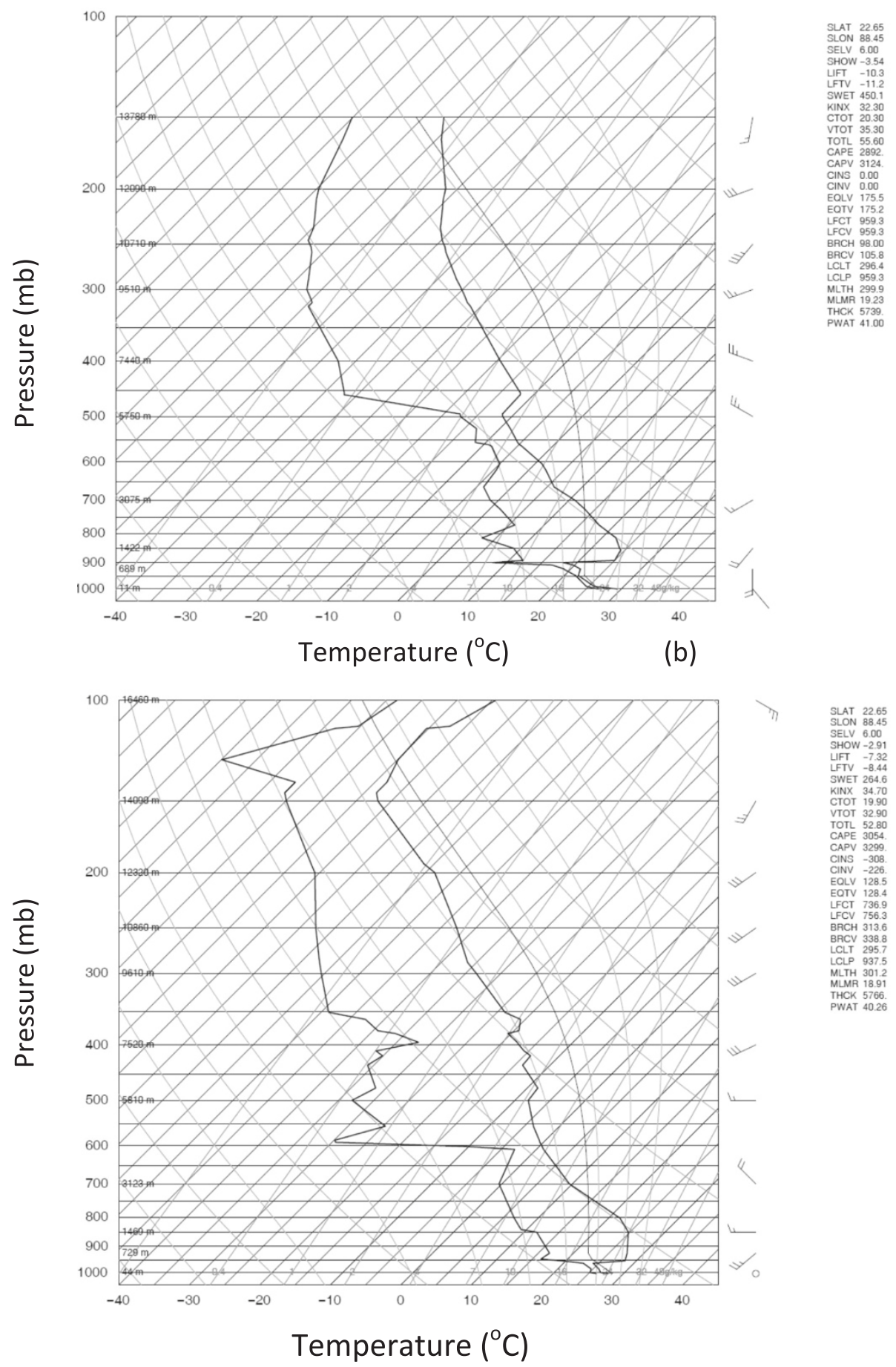

Figure 2 Skew-T diagram of 11 May 2009 (a) and 6 May 2009 (b). Obtained at 0000 hours (UTC) at Kolkata.

Figure 5 shows the electric field changes induced by lightning discharges during whole period of this thunderstorm. On May 11, the rate of electric field changes induced by lightning reached up to 170 changes per
5 min during the active phase of the thunderstorm, whereas on May 6 and May 12, the rate reached up to 44 and 74 changes per 5 min, respectively. That the peak lightning flash rate of the May 11 thunderstorm was 


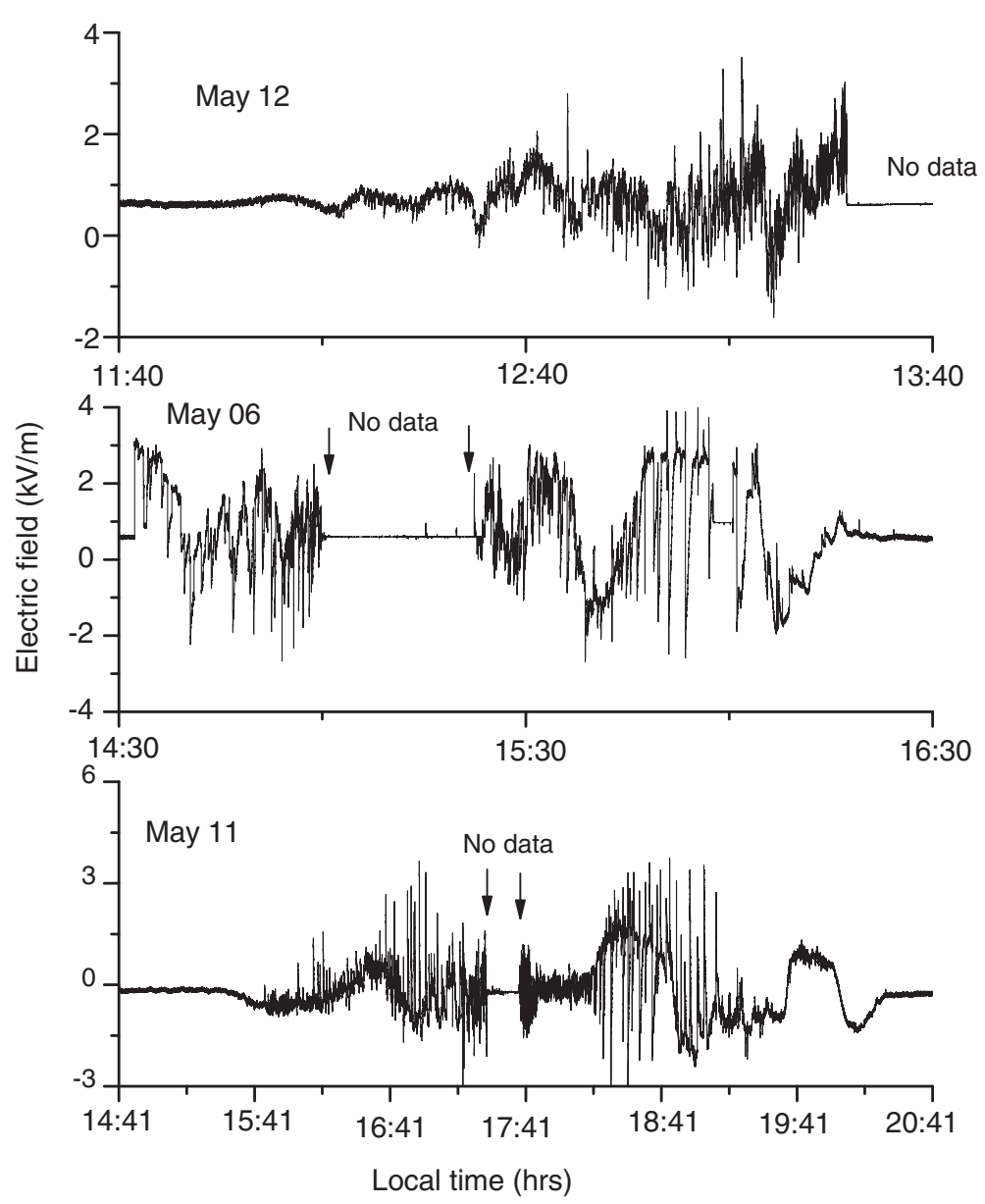

Figure 3 Variations of electric field measured beneath the thunderstorms. 11 May 2009, 6 May 2009, and 12 May 2009.

more than double that of both the May 6 and May 12 thunderstorms also confirms that the May 11 thunderstorm was most severe. As shown in Figure 5, most of the electric field changes produced by lightning on May 11 were of positive polarity, while those recorded on May 6 and May 12 were of negative polarity. Furthermore, according to Figure 5, about 20 and $35 \mathrm{~min}$ of data were lost on May 6 and May 12, respectively, due to power failure.

\section{Maxwell current density measurements}

The studies performed by Krider and Musser (1982), Deaver and Krider (1991), Blakeslee (1984), Nisbet (1985), Browning et al. (1987), and Pawar and Kamra (2009) have shown that the surface value of Maxwell current density is dominated by the displacement current density, and that it can therefore be effectively used to study charging processes inside a thundercloud. Measurements by Krider and Musser (1982), Deaver and Krider (1991), and Pawar and Kamra (2009) have shown that for thunderstorms of non-inverted polarity, the
Maxwell current density remains positive, increasing during the active stage and decreasing during the dissipation stage. Pawar and Kamra (2009) have reported negative Maxwell current densities for inverted polarity thunderstorms and that its magnitude is strongly positively correlated with the lightning flash rate. Figure 6 shows the Maxwell current density measured below the May 11, and the May 6 and May 12 thunderstorms in 2009. As shown in Figure 6, the average Maxwell current density was positive for the May 6 and May 12 thunderstorms, whereas it was negative for the May 11 thunderstorm. To make this point clear, we have plotted 5-min averages of the Maxwell current densities for all three thunderstorms in Figure 7. The lightning-induced spikes have been removed manually while averaging the Maxwell current density. As shown by Krider and Musser (1982) and Pawar and Kamra (2009), the Maxwell current density is dominated by the displacement current during thunderstorms. Polarity of the Maxwell current is determined by accumulations of electric charges overhead. Positive (negative) displacement current at 


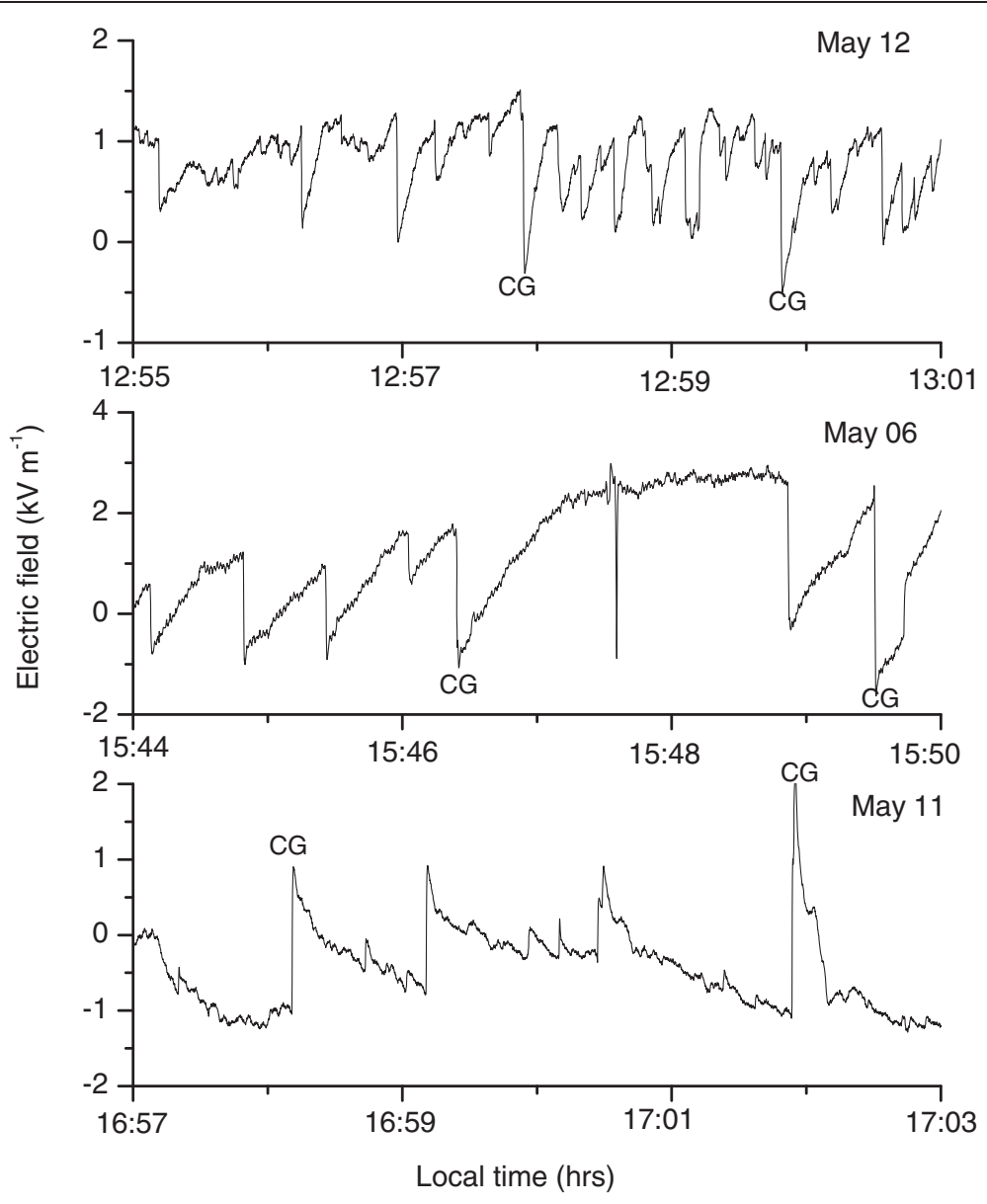

Figure 4 Same as Figure 3 but on extended scale during active stage of the thunderstorm.

ground means accumulation of negative (positive) charge overhead. The negative Maxwell current density clearly suggests the generation of positive dipole in the lower portion of cloud, while positive Maxwell current density suggests either negative dipole or dipole indicative of noninverted polarity in the lowermost portion of cloud. This confirms that the average Maxwell current density is positive for the May 6 and May 12 thunderstorms, indicating generation of negative charge in the lowermost portion of cloud as observed by Deaver and Krider (1991) in thunderstorms of non-inverted polarity. The Maxwell current density is negative for the May 11 thunderstorm, indicating inverted polarity charge structure as observed by Pawar and Kamra (2009).

\section{AOD measurements}

Many studies have shown that the enhancements in cloud condensation nuclei in the boundary layer, due to fire or other sources of natural pollution, will lead to a reduction in droplet size and suppression of coalescence. This may enhance the liquid water content in the mixed-phase region and thereby also account for the enhanced percentages of positive ground flashes (Lyons et al. 1998; Murray et al. 2000; Williams et al. 2005). The study site is situated in the Indo-Gangetic Basin (IGB) region, known for its very high aerosol concentrations owing to its unique topography, and for its high population and industrial density. Previous studies conducted in this region indicate high emissions of various anthropogenic aerosols from different sources (Rengarajan et al. 2007; Tiwari et al. 2010). It has been observed that during the pre-monsoon or summer seasons, this region receives large amounts of natural dust aerosols, transported from neighboring desert regions (i.e., from the Thar Desert) in West India (Dey et al. 2004; Pandithurai et al. 2008). We have plotted the AOD for this region in Figure 8 , measured by MODIS during May 2009. The AOD data was obtained from a level-3 MODIS gridded atmosphere daily global joint product (MOD08_D3). It contains a $1 \times 1$ degree grid of averaged daily values of parameters related to atmospheric aerosol particle properties, total ozone burden, atmospheric water vapor, optical 


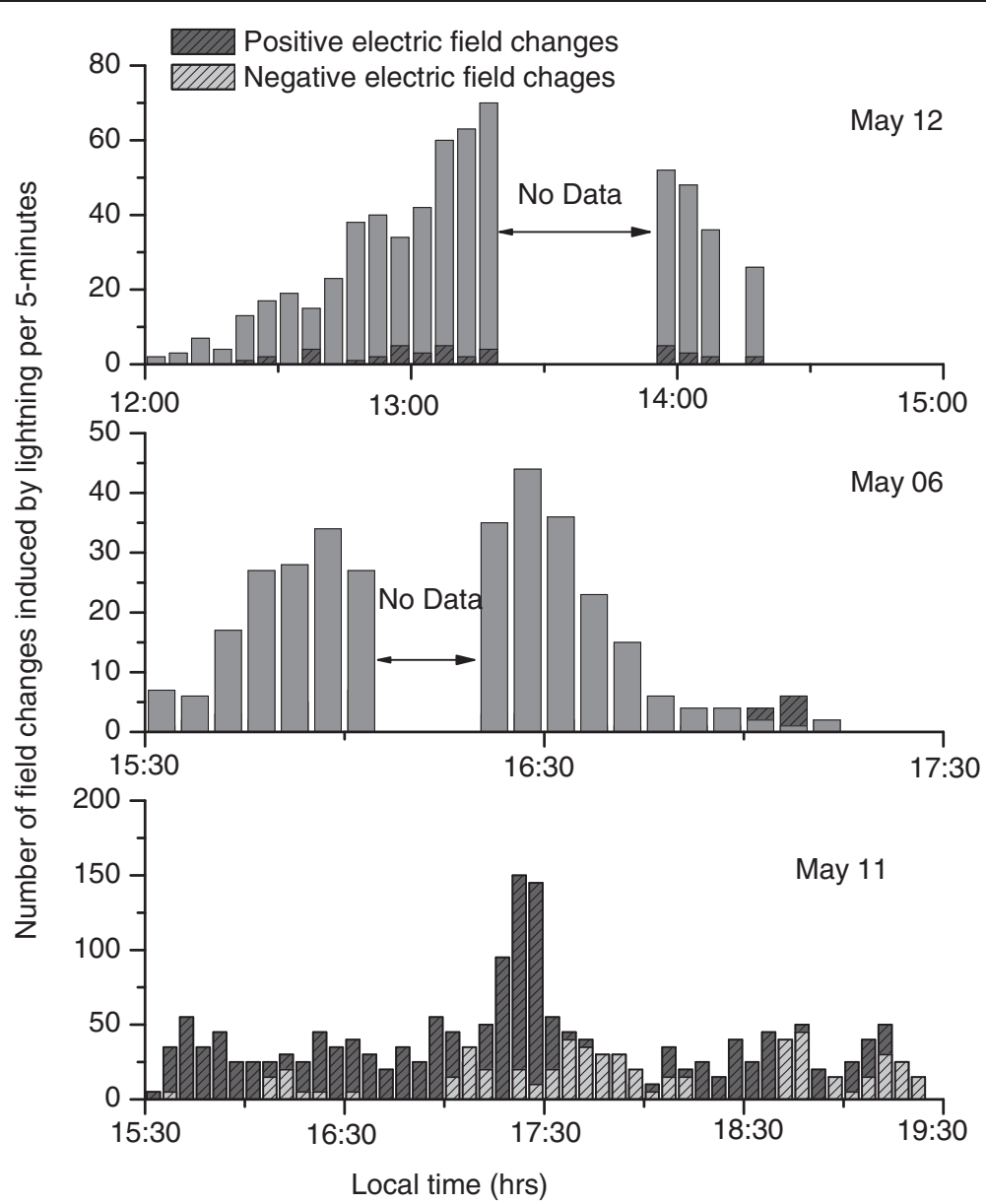

Figure 5 Cumulative number of positive and negative field changes per $\mathbf{5}$ min induced by lightning discharges. These are observed during thunderstorms on 11 May 2009, 6 May 2009, and 12 May 2009.

and physical cloud properties, and atmospheric stability indices. We took the daily averaged AOD at $550 \mathrm{~nm}$ from MODIS-Terra Version 5. Those data for which cloud cover was greater than $20 \%$ were excluded from analysis while averaging. Hence, the data gaps in Figure 8. A maximum of AOD concentration is observed on 10 May 2009, and there are large day-to-day variations. AOD data could not be included for 11 May 2009, as it was a cloudy day.

\section{Discussion}

\section{Electrical structure of the thunderstorm}

Previous studies have revealed that in thunderstorms with non-inverted polarity charge structures (with midlevel negative and upper level positive charge regions), most of the electric field changes produced by lightning are of negative polarity, indicating removal of negative charge from overhead (Jacobson and Krider 1976; Livingston and Krider 1978; Mohanty and Pradeep Kumar 2004; Pawar and Kamra 2004). Our observations of electric field changes produced by lightning, of
Maxwell current densities, and of recovery curves of the electric field during the thunderstorms of 6 May 2009 and 12 May 2009, indicate the removal of negative charge from overhead by lightning and buildup of negative charge after lightning. Therefore, it is clear from the electric field and Maxwell current density data for those 2 days that these thunderstorms had non-inverted polarity charge structures.

The electric field changes produced by lightning discharges observed during the thunderstorm on 11 May 2009 indicate removal of positive charge from overhead (Figures 4 and 5). Although it is difficult to distinguish the CG from the IC discharges based only on singlepoint observations of the electric field and Maxwell current data, most of the visually confirmed CG discharges were found to be transporting positive charge to the ground on May 11. The recovery curves of the electric field following those lightning discharges show buildup of positive charge inside the thundercloud. Furthermore, the Maxwell current record measured during 


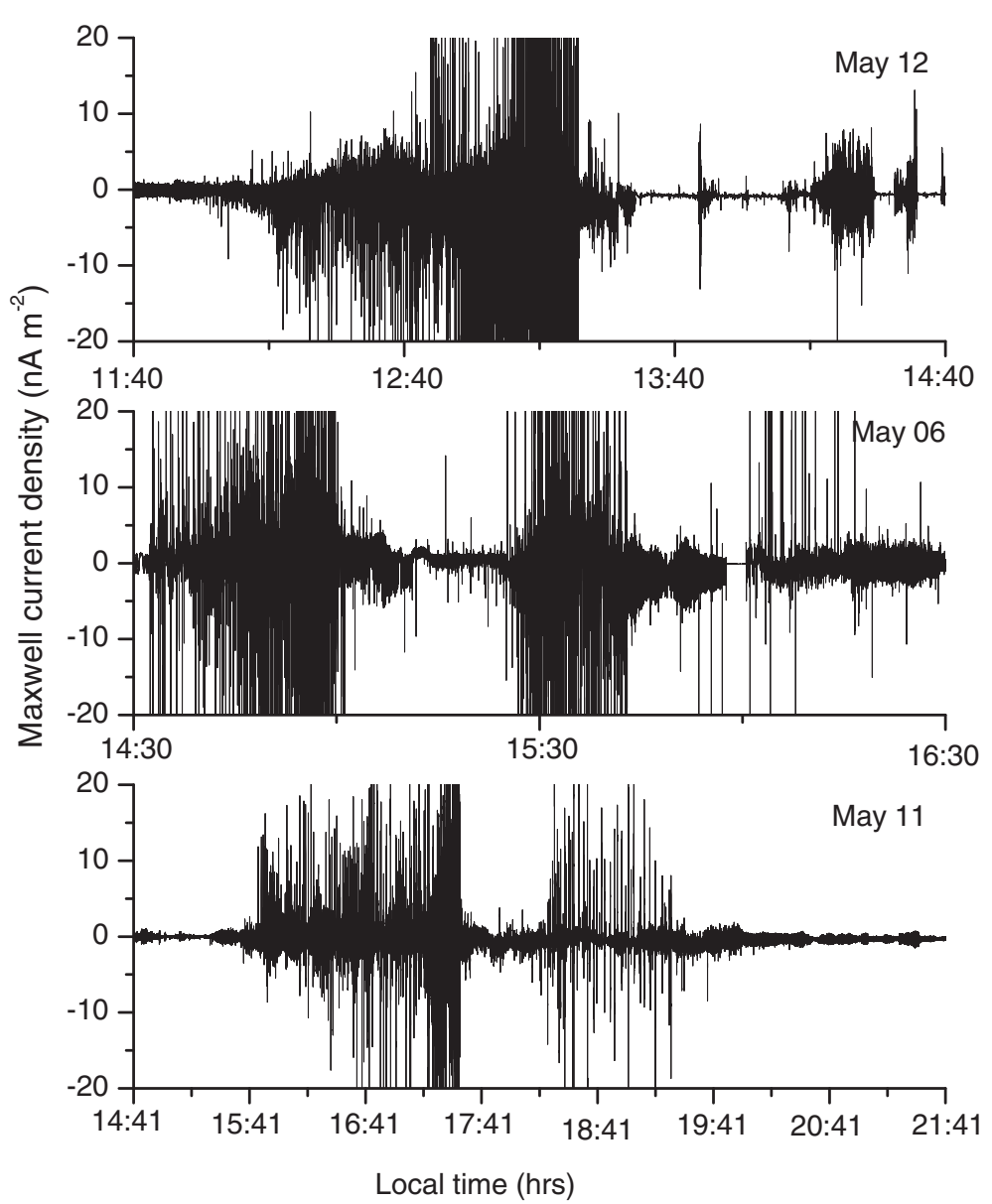

Figure 6 Variations of Maxwell-current density measured beneath thunderstorms. 11 May 2009, 6 May 2009, and 12 May 2009.

this thunderstorm is negatively valued for most of its duration. The electric field and Maxwell current patterns observed during this storm clearly suggest that the lowermost dipole of this thunderstorm was negative. Unfortunately, it is not possible to make inferences about other charge regions inside the thundercloud based solely on surface measurements of the electric field and the Maxwell current density. However, the recovery curves of the electric field following positive CG discharges and negative Maxwell current densities during those discharges clearly suggest the presence of strong negative dipole (i.e., positive charge below and negative charge above it) in the lower portion of this thundercloud. Many studies have shown that prevalence of positive CG discharges, IC discharges of inverted polarity, and negative Maxwell current density are indicators of inverted polarity thunderstorms. Therefore, our electric field and Maxwell current data clearly indicate that this thunderstorm had an inverted polarity charge structure. Although not often observed, formation of such thunderstorms over this region is also not unusual (Gopalakrishnan et al. 2010).
Limitations of using single-point surface measurements of the electric field and the Maxwell current to infer the charge structure of a thundercloud are well known. The distance between the thundercloud and the point of observation, and its vertical structure are important to make inferences about charge structures when observations from only one station are available. To confirm that the May 11 thunderstorm was very close or almost above the observatory, we used the Doppler RADAR located at Kolkata located about $120 \mathrm{~km}$ from the study site. The Doppler RADAR records show the initiation of a thunderstorm northward of the observatory, about $15 \mathrm{~km}$ from the study site at about 1524 hours. It moved toward the observatory and quickly developed into a severe thunderstorm within half an hour. Figure 9 shows the RADAR picture of the thunderstorm observed by the Kolkata Doppler RADAR at 1609 hours. As shown in Figure 9, the thunderstorm had already developed into a squall line of more than $100 \mathrm{~km}$ in length by 1600 hours. The width of this thunderstorm was about $20 \mathrm{~km}$ and its center about $5 \mathrm{~km}$ from the study site. The top of the thundercloud and 


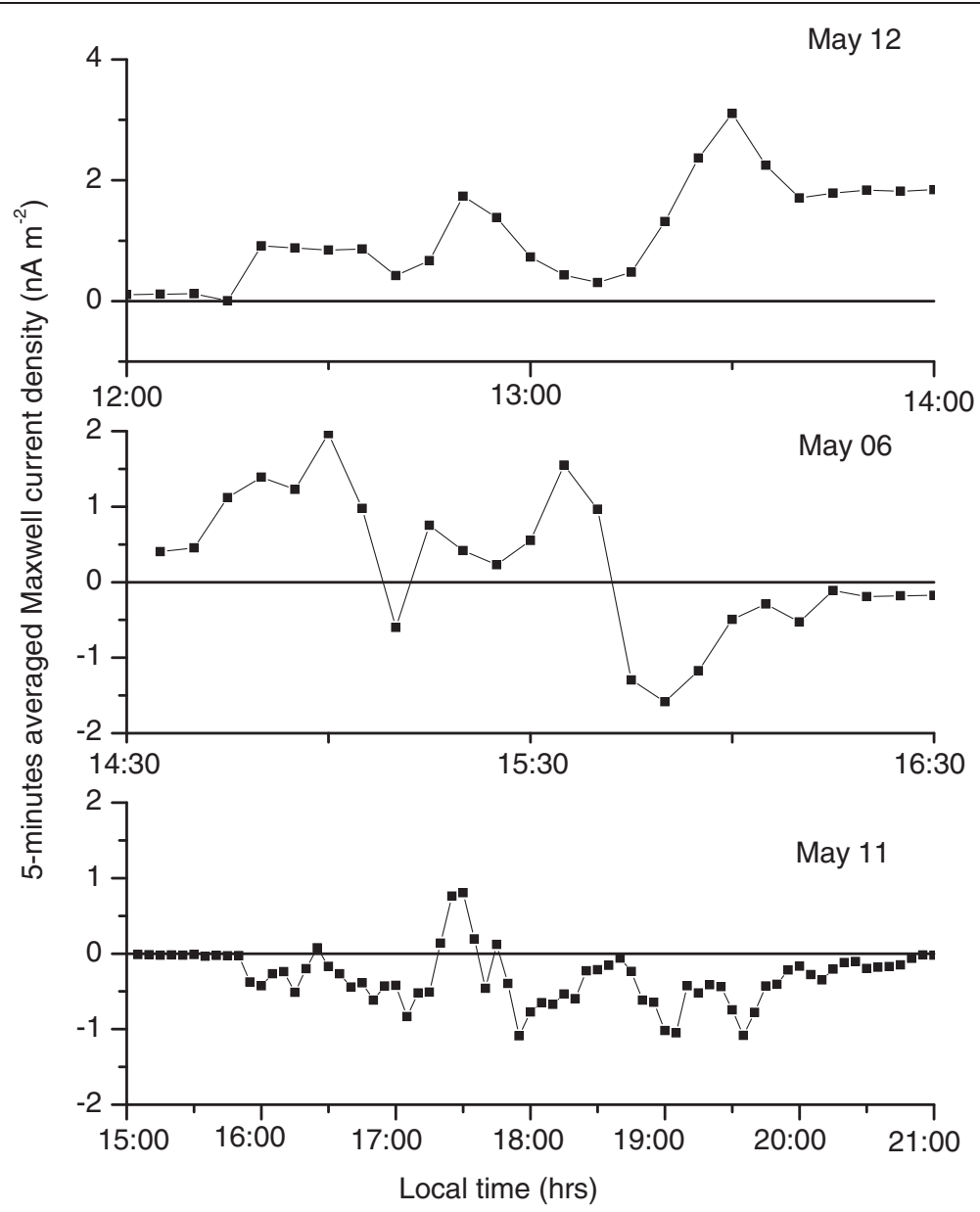

Figure 7 Five-minute averages of Maxwell current density measured during thunderstorms. 11 May 2009, 6 May 2009, and 12 May 2009.

45-dBZ echoes reached altitudes of up to 18 and $16 \mathrm{~km}$ above mean sea level, respectively, indicating a very severe thunderstorm. The thunderstorm further moved over the observatory and dissipation started about 1734 hours.

\section{Possible causes of inverted polarity charge structure}

Many laboratory and field experiments have clearly shown that inverted polarity in thunderstorms is the result of superlative liquid water content in the mixedphase region (Williams et al. 2005). One or more of the following factors can account for superlative liquid water content in the mixed-phase region, i.e., strong instability, strong updraft, greater cloud base height, and high aerosol concentration. In our observation, as shown in Figure 2, CAPE was very high $3,124 \mathrm{~J} / \mathrm{kg}$ on 11 May 2009. In addition, it should be noted here that the vertical distribution of CAPE was very peculiar on that day. As can be seen in Figure 2, most of the CAPE is concentrated in the 5- to $10-\mathrm{km}$ altitude range. Even though the CAPE was very high $(3,054 \mathrm{~J} / \mathrm{kg})$ on May 6 , it was distributed over a larger region compared to May 11 . The high CAPE and its vertical distribution clearly suggest that the updraft could be high in the mixed-phase region on May 11. As shown in Figure 8, the aerosol concentration was also very high on May 11 compared to the other days.

Strong instability and updraft can account for the high cloud water concentrations in the mixed-phase region and are thus necessary conditions for formation of inverted polarity thunderstorms to occur. The observations of Albrecht et al. (2011) and Carey and Buffalo (2007), which show a greater number of positive storms occurring in environments associated with stronger conditional instability and larger buoyancy in the mixedphase region compared to negative storms, support this idea. However, these are not sufficient conditions for clustered positive lightning and inverted polarity storms (MacGorman and Burgess 1994; Williams et al. 2005). Lyons et al. (1998) indicate aerosols may play some role in the formation of inverted polarity charge structures. Aerosols can affect the charge generation process by two 


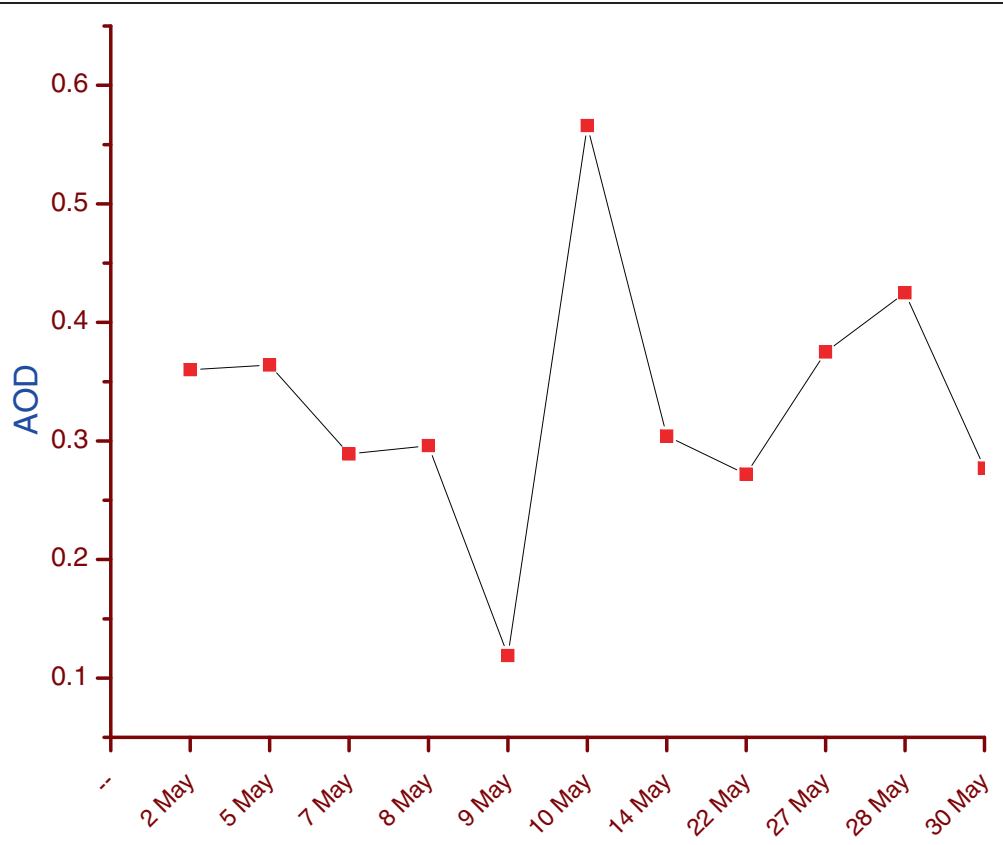

Figure 8 Daily values of AOD as measured by MODIS during May 2011 and 2009. AODs on cloudy dates are not plotted.

ways. First, as suggested by Williams et al. (2002), increased numbers of aerosols can lead to reduction in drop size and transportation of greater amounts of liquid water into the mixed-phase region. Second, as shown by Pawar and Kamra (2009), if air mass contains more ice nuclei, concentration of ice crystals can be sufficiently high at lower altitudes or higher temperatures for sign reversal to occur in the process of charge generation.

The thunderstorm observed on 11 May 2009, showing signs indicative of inverted polarity charge structure, formed in an environment with strong updraft and high instability. As shown in Figure 9, the Doppler RADAR shows a squall line of more than $600 \mathrm{~km}$ in length and the top of the cloud reached altitudes of up to $18 \mathrm{~km}$. Radiosonde data also indicated the possibility of strong updraft in the mixed-phase region. Furthermore, aerosol concentration was very high on May 11 compared to the other days. Moreover, as stated in section 'AOD measurements', there are abundant natural aerosols transported from neighboring desert regions (i.e., from the Thar Desert) of India at high altitudes that may favor enhancement of ice nuclei inside thundercloud. The National Centers for Environmental Prediction (NCEP) 5-day back trajectory analysis confirms that the winds at high level originated from desert regions on 10 May 2009 (Figure 10). As seen from Figure 10, on other days during which we observed non-inverted polarity thunderstorms, the winds are of oceanic origin at all levels.
Our observations hint at the influx of natural aerosols from neighboring desert regions on May 11, which might have caused larger ice nuclei concentrations in the mixed-phase region, creating favorable conditions for the formation of inverted polarity charge structures on May 11.

Our observations not only show high concentrations of aerosols but also that the degree of concentration of ice nuclei may be playing an important role in the formation of inverted polarity charge structures in thunderclouds. Our study site located in the IGB region is known for its very high aerosol concentrations owing to its unique topography. During the pre-monsoon or summer seasons, this region receives large amounts of natural dust aerosols, transported from neighboring desert regions (i.e., from the Thar Desert) (Dey et al. 2004; Pandithurai et al. 2008). These dust particles can act as ice nuclei. Our observations on 11 May 2009 are similar to the observations of Pawar and Kamra (2009), during which back trajectories were shown to be indicative of aerosol transport from desert regions on the day when an inverted polarity thunderstorm was observed. Small inverted polarity thunderstorms reported by Gopalakrishnan et al. (2010) in this region and by Pawar and Kamra (2002, 2004, and 2009) at Pune, India, support the idea that large ice nuclei concentrations can play an important role in the alteration of charge structures of thunderstorms with moderate or low instability. Many laboratory experiments (Baker et al. 1987; Williams 


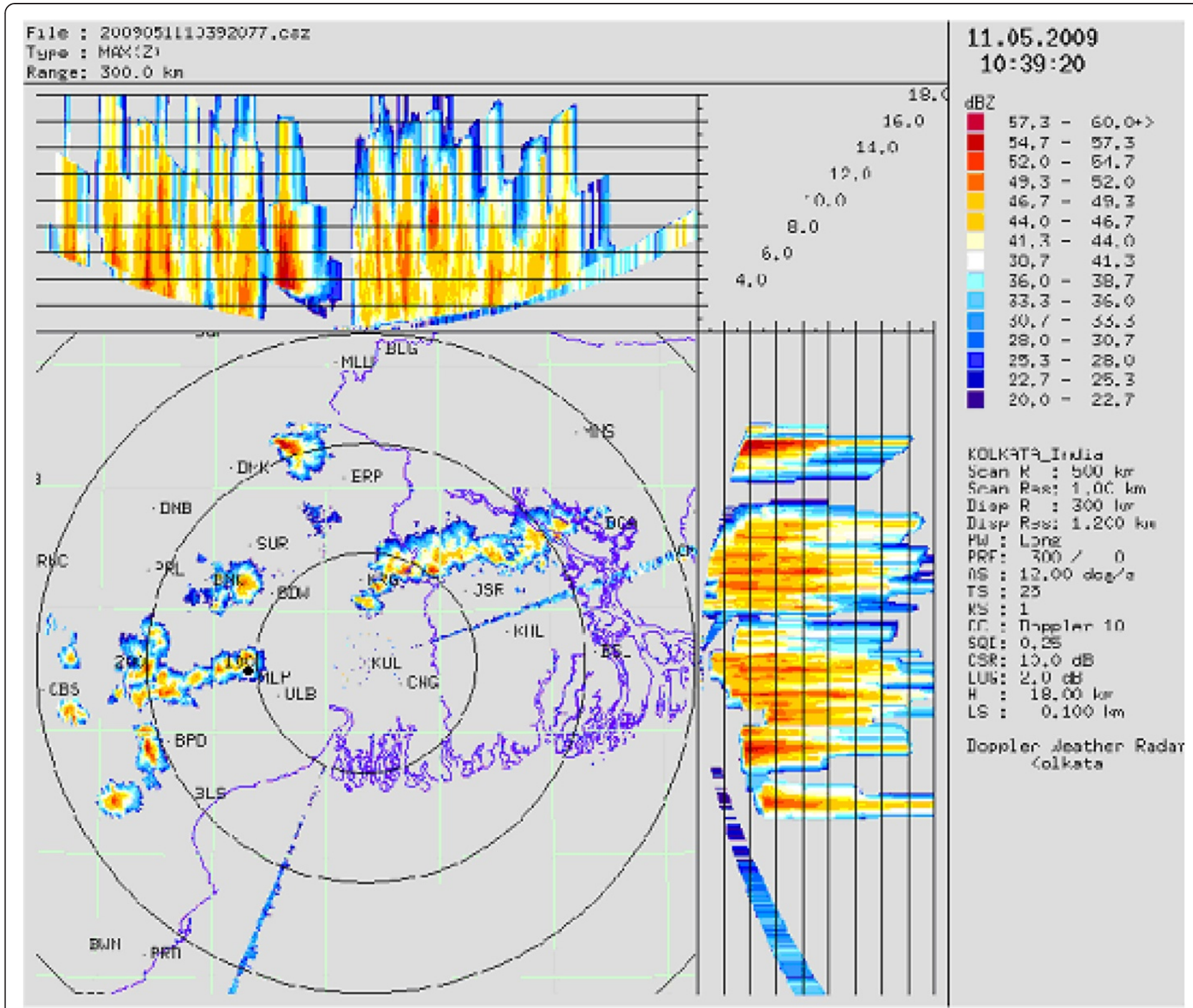

Figure 9 RADAR picture taken by Kolkata Doppler radar at 1039 hours (UTC). The black dot indicates the observation site.

et al. 1991; Caranti et al. 1991) suggest that dominant positive charge will appear on larger precipitation particles in the lower portion of the mixed-phase region if ice saturation is maintained.

The authors are aware that the aerosol and/or ice nuclei concentrations cannot influence the polarity of thunderstorms by themselves. More observations of such thunderstorms are required to confirm our proposal that increased optical depth leads to changes in ice nuclei, which in turn affect the charging mechanism. Although many severe thunderstorms occur over this area during pre- and post-monsoon seasons, occurrences of thunderstorms with inverted polarity are rare. We have made observations of thunderstorms over this region and over Pune, for three seasons and for about 2 decades, respectively. However, only three to four thunderstorms with inverted polarity have been observed over these regions.
Gopalakrishnan et al. (2010) have already reported one such thunderstorm over this region. Occurrences of such inverted polarity thunderstorms over other parts of India are also few. Pawar and Kamra (2002, 2004, and 2009) have reported some of such thunderstorms over Pune. There are no other reports of such thunderstorms from any other part of India. This complicates the task of finding a robust statistical test to corroborate our claim. In the absence of such a test, our proposal is merely speculative. Nevertheless, observations of greater optical depth prior to the occurrence of a severe thunderstorm in the present case do lend support to our speculation.

\section{Conclusions}

Electric field and Maxwell current density measurements clearly illustrate that the 11 May 2009 thunderstorm had 

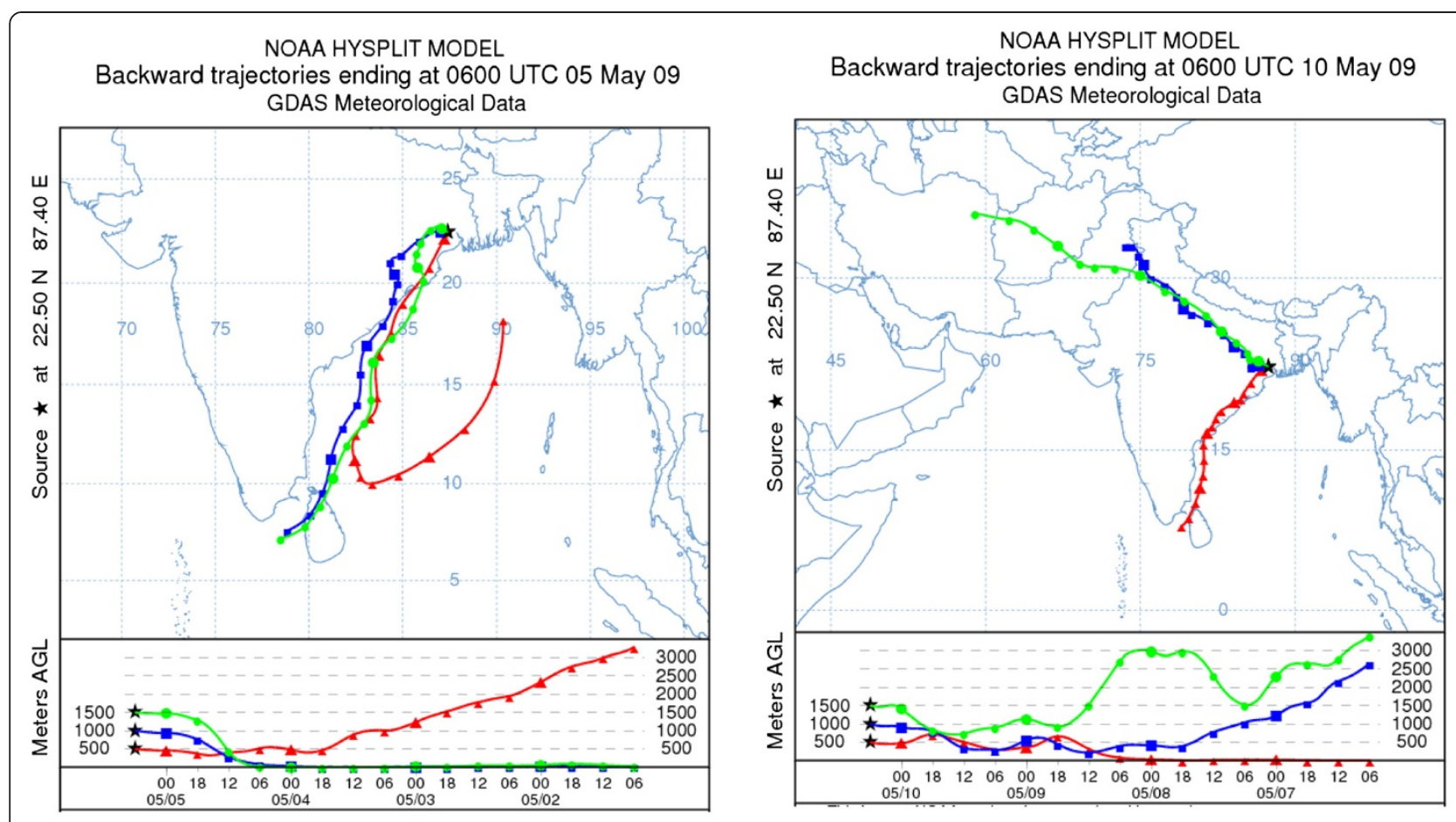

NOAA HYSPLIT MODEL

Backward trajectories ending at 0600 UTC 11 May 09 GDAS Meteorological Data

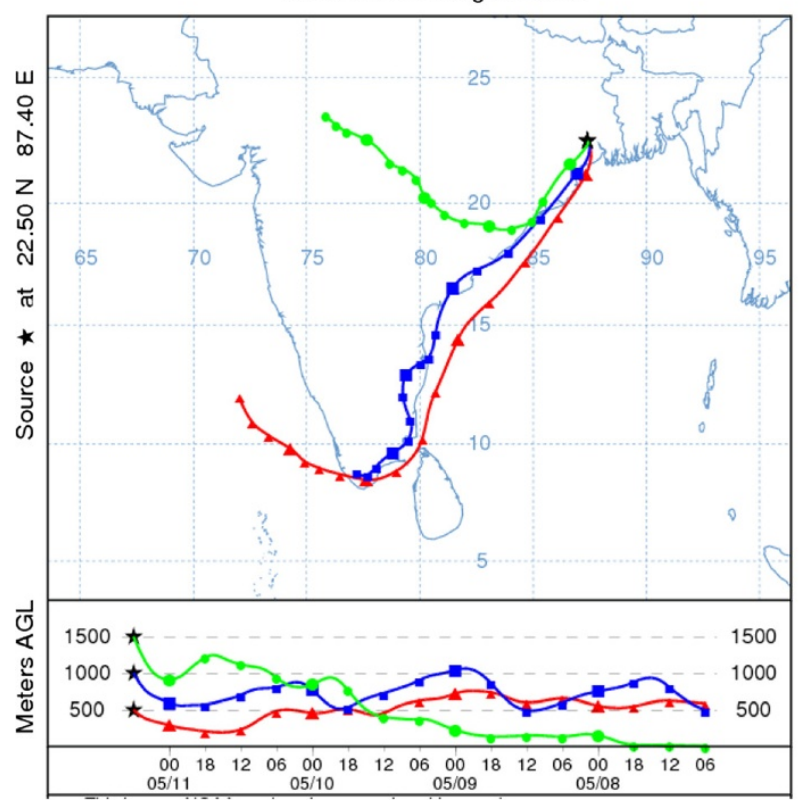

NOAA HYSPLIT MODEL

Backward trajectories ending at 0600 UTC 12 May 09 GDAS Meteorological Data

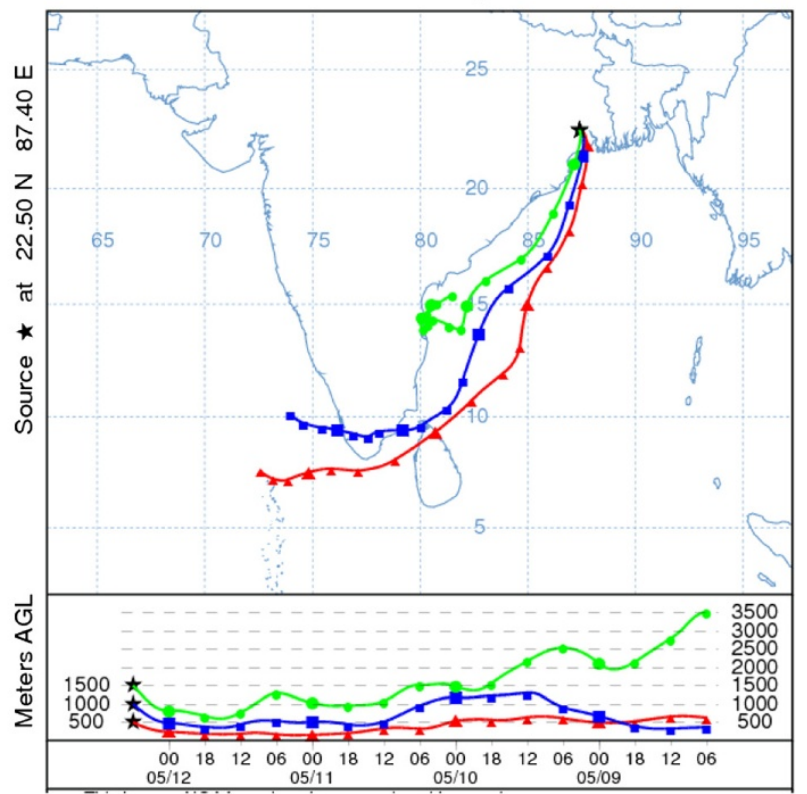

Figure 10 Five-day trajectories of air masses at different altitudes. 5 May 2009, 10 May 2009, 11 May 2009, and 12 May 2009.

a strong and dominant positive charge region in the lower portion of cloud. Analysis of back trajectories (Figure 10) and satellite-derived AOD observations (Figure 8) lend support to our argument that the May 11 thundercloud formed in an environment with high ice nuclei concentration, i.e., high compared to other thunderstorms. Therefore, our studies suggest that a large ice nuclei concentration can produce dominant positive charge in the lower portion of the mixed-phase region by maintaining ice saturation. 


\section{Competing interests}

The authors declare that they have no competing interests.

\section{Authors' contributions}

SDP, VG, and PM formulated and participated in the experiment and analyzed the results. AAS participated in discussion on aerosol effects. DML assisted in the manuscript preparation. All authors read and approved the final manuscript.

\section{Acknowledgements}

The authors express their sincere gratitude to Dr. M Mandal of IT, Kharagpur for providing the logistics necessary to conduct fieldwork, and are also grateful to the Department of Science and Technology, Government of India, for funding this study under the Severe Thunderstorm-Observation and Regional Modeling (STORM) program. A part of this work was carried out under the DST-RFBR Indo-Russian program (DST/INT/RFBR/P-158). The authors thank Dr. D. Pradhan of IMD, Kolkata for providing RADAR data, and are also grateful to the NOAA Air Research Laboratory (ARL) for providing the HYSPLIT transport and dispersion model and the READY website (http://www.arl.noaa.gov/ready.html). Finally, the authors thank the Department of Atmospheric Science, University of Wyoming, for allowing access to their data.

\section{Author details}

${ }^{1}$ Indian Institute of Tropical Meteorology, Pune, India. ${ }^{2}$ AI Voeikov Main Geophysical Observatory, St. Petersburg, Russia.

Received: 5 August 2013 Accepted: 6 March 2014 Published: 16 June 2014

\section{References}

Albrecht RI, Morales CA, Silva Dias MAF (2011) Electrification of precipitation systems over the Amazon: physical processes of thunderstorm development. J Geophys Res 116:D08209, doi:10.1029/2011JD014756

Baker B, Baker MB, Jayaratne ER, Latham J, Saunders CPR (1987) The influence of diffusional growth rates on the charge transfer accompanying rebounding collisions between ice crystals and soft hailstones. QJR Meteorol Soc 113:1193-1215, doi:10.1256/ smsqj.47806

Blakeslee RJ (1984) The electric current densities beneath thunderstorms. Ph. D. dissertation, University of Arizona, TX, USA

Browning GL, Tzur I, Roble RG (1987) A global time-dependent model of thunderstorm electricity I: mathematical properties of the physical and numerical models. J Atmos Sci 44:2166-2177

Caranti GM, Avila EE, Re MA (1991) Charge transfer during individual collisions in ice growing from vapor deposition. J Geophys Res 96:15365-15375

Carey LD, Buffalo KM (2007) Environmental control of cloud-to-ground lightning polarity in severe storms. Mon Weather Rev 135:1327-1353, doi:10.1175/ MWR3361

Carey LD, Rutledge SA (1998) Electrical and multiparameter radar observations of a severe hailstorm. J Geophys Res 103(13):979-14 000

Carey LD, Rutledge SA (2003) Characteristics of cloud-to-ground lightning in severe and nonsevere storms over the central United States from 1989-1998. J Geophys Res 108:4483, doi:10.1029/2002JD002951

Carey LD, Rutledge SA, Petersen WA (2003) The relationship between severe weather reports and cloud-to-ground lightning polarity in the contiguous United States from 1989 to 1998. Mon Weather Rev 131:1211-1228

Deaver LE, Krider EP (1991) Electric fields and current densities under small Florida thunderstorms. J Geophys Res 96:22273-22281

Dey S, Tripathi SN, Singh RP, Holben BN (2004) Influence of dust storms on the aerosol optical properties over the Indo-Gangetic basin. J Geophys Res 109:D20211, doi:10.1029/2004JD004924

Gopalakrishnan V, Pawar SD, Murugavel P, Johare KP (2010) Electrical characteristics of thunderstorms in the Eastern part of India. J Atmos Solar Terr Phys 73:1876-1882, doi:10.1016/j.jastp.2011.04.022

Jacobson EA, Krider EP (1976) Electrostatic field changes produced by Florida lightning. J Atmos Sci 33:103-117

Kamra AK, Pawar SD (2007) Evolution of lightning in an isolated hailstorm of moderate size in the tropics. J Geophys Res 112:D20205, doi:10.1029/ 2006JD007820
Krehbiel PR, Thomas RJ, Rison W, Hamlin T, Harlin J, Davis M (2000) GPS-based mapping system reveals lightning inside storms. Eos Trans Amer Geophys Union 81:21-25

Krider EP, Musser JA (1982) Maxwell currents under thunderstorms. J Geophys Res 87:11171-11176

Lang TJ, Rutledge SA (2002) Relationships between convective storm kinematics, precipitation, and lightning. Mon Weather Rev 130:2492-2506

Lang TJ, Miller LJ, Weisman M, Rutledge SA, Barker LJ III, Bringi VN, Chandrasekar V, Detwiler A, Doesken N, Helsdon J, Knight C, Krehbiel P, Lyons WA, MacGorman D, Rasmussen E, Rison W, Rust WD, Thomas R (2004) The Severe Thunderstorm Electrification and Precipitation Study (STEPS). Bull Am Meteorol Soc 85:1102-1125

Livingston JM, Krider EP (1978) Electric fields produced by Florida thunderstorms. J Geophys Res 83:385-401

Lyons WA, Nelson TE, Williams ER, Cramer J, Turner T (1998) Enhanced positive cloud-to-ground lightning in thunderstorms ingesting smoke. Science 282:77-81

MacGorman DR, Burgess DW (1994) Positive cloud-to-ground lightning in tornadic storms and hailstorms. Mon Weather Rev 122:1671-1697

Mohanty M, Pradeep Kumar P (2004) Electric field measurements of overhead thunderstorms at a tropical station using network of plate antennas. Indian J Radiol \& Space Phys 33:310-315

Murray N, Orivlle R, Huffines G (2000) Effect of pollution from Central American fires on cloud-to-ground lightning in May 1998. Geophys Res Lett 28:2597-2600

Nisbet JS (1985) Thundercloud current determination from measurements at Earth's surface. J Geophys Res 90:5840-5856

Pandithurai G, Dipu S, Dani KK, Tiwari S, Bisht DS, Devara PCS, Pinker RT (2008) Aerosol radiative forcing during dust events over New Delhi, India. J Geophys Res 113:D13209, doi:10.1029/2008JD009804

Pawar SD, Kamra AK (2002) Recovery curves of the surface electric field after lightning discharges occurring between the positive charge pocket and negative charge centre in a thundercloud. Geophys Res Lett 29:2108-2111

Pawar SD, Kamra AK (2004) Evolution of lightning and the possible initiation/ triggering of lightning discharges by the lower positive charge centre in an isolated thundercloud in Tropics. J Geophys Res 109:D02205, doi:10.1029.2003JD003735

Pawar SD, Kamra AK (2009) Maxwell current density characteristics below isolated thunderstorms in tropics. J Geophys Res 114:D04208, doi:10.1029/ 2008JD010348

Qie X, Kong X, Zhang G, Zhang T, Yuan T, Zhou Y, Zhang Y, Wang H, Sun A (2005) The possible charge structure of thunderstorm and lightning discharges in northeastern verge of Qinghai-Tibetan Plateau. Atmos Res 76:231-246

Rengarajan R, Sarin MM, Sudheer AK (2007) Carbonaceous and inorganic species in atmospheric aerosols during wintertime over urban and high-altitude sites in North India. J Geophys Res 112:D21307, doi:10.1029/2006JD008150

Rust WD, MacGorman DR (2002) Possibly inverted-polarity electrical structures in thunderstorms during STEPS. Geophys Res Lett 29:29, doi:10.1029/ 2001 GL014303

Rust WD, MacGorman DR, Arnold RT (1981) Positive cloud-to-ground lightning flashes in severe storms. Geophys Res Lett 8:791-794

Rust WD, MacGorman DR, Bruning EC, Weiss SA, Krehbiel PR, Thomas RJ, Rison W, Hamlim T, Harlin J (2005) Inverted polarity electrical structures in thunderstorms in the Severe Thunderstorm Electrification and Precipitation Study (STEPS). Atmos Res 76:247-271, doi:10.1016/j.atmosres.2004.11.029

Stolzenburg M (1994) Observations of high ground flash densities of positive lightning in summertime thunderstorms. Mon Weather Rev 122:1740-1750

Tiwari S, Srivastava AK, Bisht DS, Bano T, Singh S, Behura S, Srivastava Manoj K, Chate DM, Padmanabhamurty B (2010) Black carbon and chemical characteristics of PM10 and PM2.5 at an urban site of North India. J Atmos Chem 62:193-209, doi:10.1007/s10874-010-9148

Vonnegut B, Moore CB (1958) Giant electrical storms. In: Smith LG (ed) 2005: Thermodynamic conditions favorable to superlative thunderstorm updraft, mixed phase microphysics and lightning flash rate, vol 76, Atmos Res., pp 288-306

Wiens KC, Rutledge SA, Tessendorf SA (2005) The 29 June 2000 suppercell observed during STEPS. Part II: lightning and charge structure. J Atmos Sci 62:4151-4177

Williams ER, Zhang R, Rydock J (1991) Mixed-phase microphysics and cloud electrification. J Atmos Sci 48:2195 
Williams E, Rosenfeld D, Madden N, Gerlach J, Gears N, Atkinson L, Dunnemann N, Frostrom G, Antonio M, Biazon B, Camargo R, Franca H, Gomes A, Lima M, Machado R, Manhaes S, Nachtigall L, Piva H, Quintiliano W, Machado L, Artaxo P, Roberts G, Renno N, Blakeslee R, Bailey J, Boccippio D, Betts A, Wolff D, Roy B, Halverson J et al (2002) Contrasting convective regimes over the Amazon: implications for cloud electrification. J Geophys Res 107(D20): LBA 50-1-LBA 50-19, doi:10.1029/2001JD000380

Williams ER, Mustak V, Rosenfeld D, Goodman S, Boccippio D (2005)

Thermodynamic conditions favorable to superlative thunderstorm updraft, mixed phase microphysics and lightning flash rate. Atmos Res 76:288-306

doi:10.1186/1880-5981-66-54

Cite this article as: Pawar et al:: Effects of environmental conditions on inducing charge structures of thunderstorms over Eastern India. Earth, Planets and Space 2014 66:54.

\section{Submit your manuscript to a SpringerOpen ${ }^{\circ}$} journal and benefit from:

- Convenient online submission

- Rigorous peer review

- Immediate publication on acceptance

- Open access: articles freely available online

- High visibility within the field

- Retaining the copyright to your article

Submit your next manuscript at $>$ springeropen.com 